\title{
AGROTÓXICOS - TOXIDADE VERSUS CUSTOS: UMA EXPERIÊNCIA DE FORMAÇÃO DE PROFESSORES COM AS QUESTÕES SOCIOCIENTÍFICAS NO ENSINO DE CIÊNCIAS

\author{
PESTICIDES-TOXICITYVERSUSCOSTS: AN EXPERIENCE OF \\ TEACHERS' FORMATION WITHTHE SOCIO-SCIENTIFIC ISSUESIN \\ SCIENCE EDUCATION
}

\author{
Nataly Carvalho Lopes ${ }^{1}$ \\ Washington Luiz Pacheco de Carvalho ${ }^{2}$
}

\begin{abstract}
RESUMO
Neste trabalho, propomos as questões sociocientíficas (QSC) como a efetivação curricular dos ideais do movimento CTSA na educação. Além disso, desenvolvemos junto a uma escola de ensino básico, em uma comunidade rural do interior do estado de São Paulo, atividades de formação permanente de professores nas discussões das QSC em sala de aula. Para compreendermos e refletirmos sobre as situações decorridas dessas práticas, consideramos a pesquisa participante e a análise de conteúdo, a partir dos registros em áudio das reuniões semanais entre os professores da escola e pós-graduandos de uma universidade próxima. Diante disto, pudemos compreender como essas questões devem fazer parte da vida das pessoas, os professores devem apresentar motivação para o trabalho, necessitam de informação, exposição dos argumentos envolvidos, devem relacionar conteúdos e currículos, mas, tudo isto, tendo em vista a necessária crítica aos aspectos que podem tornar essa prática instrumentalizada. Ao final deste recorte da pesquisa que realizamos em nível de doutorado, pudemos considerar indícios de como os professores se inseriram no processo de formação, com o envolvimento deles nas discussões e nas práticas com as QSC.
\end{abstract}

PALAVRAS-CHAVE: Formação de professores, CTSA, Questões sociocientíficas, agrotóxicos, grupos de trabalho.

\begin{abstract}
In this paper, we propose the socio-scientific issues (SSI) as an effective part of the curriculum of the ideals of the STSE movement in education. Furthermore, we have developed in a secondary school, in a rural community in the state of São Paulo, activities of continuing education for teachers in the discussions of SSI in the classroom. To understand and reflect on the situations resulting from these practices, we considered the participant research and the content analysis from the audio records of the weekly meetings between the teachers of this school and graduate students from a nearby university.Given this,we could understand how these issues should be part of people's lives, teachers must present motivation for the work, they need information,exposition of the arguments involved, mustrelate content and curricula, but, all this, aiming at the necessary critics of the aspects that can make this an

\footnotetext{
${ }^{1}$ Programa de pós-graduação em educação para a ciência, Faculdade de Ciências, Unesp campus Bauru. E-mail: naty_lopes85@hotmail.com.

${ }^{2}$ Departamento de física e química, Faculdade de Engenharia de Ilha Solteira, Unesp campus Ilha Solteira. E-mail: washcar@dfq.feis.unesp.br.

AMAZÔNIA - Revista de Educação em Ciências e Matemáticas V.9 - no 17 - jul. 2012/dez. 2012, p.27-48.
} 
instrumentalized practice. At the end of this clipping of our doctoral research, we were able to consider evidences on how teachers were inserted in the training process, with their involvement in the discussions and practices with the ISS.

KEYWORDS: Teacher, STSE, socio-scientific issues, pesticides, working groups.

\section{INTRODUÇÃO}

Sem dúvida, os problemas que permeiam a sociedade atual também são visíveis no ensino de ciências, como reprodução social, mas também as contradições entre o discurso dos atores que propõem leis e currículos educacionais e o que é percebido nas escolas e expresso na prática docente. Um dos problemas que procuramos expor diz respeito à inexpressividade da sociedade civil, quando o assunto é a sua compreensão e a sua participação nas decisões e nos planejamentos importantes que afetam, principalmente, o grande público. Essas decisões podem se referir à ciência, à tecnologia, à saúde, à política, à economia e à educação.

Nesse sentido, questionamos de que maneira as questões sociocientíficas (QSC), que consideramos um desdobramento do movimento Ciência, Tecnologia, Sociedade e Ambiente (CTSA), na sala de aula, podem ser tratadas na escola com o trabalho coletivo de compreensão teórica e de planejamento das aulas pelos professores?

Para descrever esta situação, trabalhamos por dois anos em uma escola de ensino básico, em uma cidade agrícola do interior do estado de São Paulo, com a constituição de um pequeno grupo de pesquisa (PGP), com a participação de professores da escola e da universidade. Este PGP atua na formação de professores, com estudos e discussões teóricas, além da elaboração conjunta de práticas em sala de aula com as QSC. Neste PGP, a QSC que foi inicialmente discutida se referia a um problema grave da cidade: a contaminação pelo uso de agrotóxicos, por agricultores, que são pais dos alunos da escola, que normalmente também trabalham na lavoura e passam a ser contaminados, apresentando quadros agudos da contaminação e chegam à escola, por vezes, passando mal.

Assim, para a compreensão dessas situações, neste trabalho, discutiremos nossa concepção de formação de professores críticos, que refletem sobre a realidade e o currículo a partir dela, as QSC como metodologia de trabalho, que permitem a problematização e a transformação da realidade e a pesquisa participante, como meio para a interação entre universidade e escola. 


\section{FORMAÇÂO DE PROFESSORES CRÍTICOS}

De acordo com Pereira (2002), há três modelos de formação de professores, os técnicos, relacionados à racionalidade técnica; os práticos, relacionados à racionalidade prática e; os críticos, relacionados à racionalidade emancipatória. Já Contreras (2002) discute outras três concepções sobre a prática docente, como o especialista técnico, o profissional reflexivo e o intelectual crítico. Embora não tenhamos a pretensão de abranger a amplitude das discussões referentes a estas perspectivas, compartilhamos neste trabalho uma concepção de formação de professores críticos.

Esta formação corresponde à abrangência de atividades dos professores, como conhecer, compreender e poder influenciar nas políticas e propostas para a educação pública, mais que suas tarefas cotidianas e burocráticas. Porém, essas ações não podem ser compreendidas de maneira desligada da prática docente, pois a escola reproduz os padrões sociais, além da própria construção do conhecimento. Ambos os aspectos devem ser entendidos como propícios de participação social, portanto, como inerentes aos conhecimentos e ao trabalho do professor.

Nessa perspectiva, a própria noção de autonomia se refere ao professor como participante de deliberações no campo educacional, assim como na prática cotidiana de sala de aula e de interação com os pares. Como afirma Contreras (2002), "a autonomia do professor em sala de aula, como qualidade deliberativa da relação educativa, se constrói na dialética entre as convicções pedagógicas e as possibilidades de realizá-las, de transformá-las nos eixos reais do transcurso e da relação de ensino" (p.198).

$\mathrm{Na}$ visão de Canário (2000), "na medida em que passam a considerar-se as dimensões colectivas do exercício do trabalho, a formação orienta-se, também, para a formação de equipas de trabalho que se formam em exercício e no contexto organizacional (de trabalho)". Tal percepção prevê a escola como lócus da formação do professor para as competências profissionais, já que o argumento do autor é no sentido das escolas não serem apenas o lugar da "aplicação" do conhecimento produzido. Assim, o produto da formação de uma comunidade crítica pode ser a produção de conhecimentos pelos professores, que diante das teorias acadêmicas podem ser frágeis, ou influenciadas por elas, mas apesar disso,

\footnotetext{
Podem servir para reforçar os valores comunitários: podem fazer com que aqueles que estão envolvidos no trabalho crítico compartilhem mais valores e crenças, ampliem suas relações se compartilham suas reflexões e trabalham conjuntamente em atuações comuns, e que atuem comumente segundo formas que sirvam aos interesses comuns (invés de uma pluralidade de interesses e perspectivas) (KEMMIS, 1993, p.25-6).
} 
Assim, são estes ideais brevemente expostos que guiam a constituição dos pequenos grupos de pesquisa na escola, onde os professores expressam seus problemas e interesses pessoais, discutem os problemas locais, da escola e da comunidade, conhecem o currículo e propõem alternativas, que julgam ser mais pertinentes às necessidades dos alunos. Portanto, as QSC passam a descrever uma parte dessa realidade e é necessário compreendermos um pouco sobre elas.

\section{AS QUESTÕES SOCIOCIENTÍFICAS - AGROTÓXICOS: TOXIDADE VERSUS CUSTOS}

Certamente, o Brasil tem evoluído no setor econômico, mas não evolui, nas mesmas proporções, nos setores sociais e educacionais. De acordo com os relatórios internacionais, estamos sempre a um passo do desenvolvimento econômico dos países mais ricos, mas distantes deles, quando o assunto é educação. Segundo a Organização para Cooperação e Desenvolvimento Econômico $\left(\mathrm{OCDE}^{3}\right)$, em 2010, o Brasil teve um crescimento econômico de 7,5\%. Entretanto, apenas cerca de $10 \%$ da população, entre 25 e 64 anos, concluem o ensino superior. Aproximadamente, $14 \%$ da população, entre 20 e 24 anos, não estudam nem trabalham e a taxa de mortalidade infantil é de 17 para 1000 nascimentos. Em contrapartida, a Alemanha, com um crescimento econômico de 3,6\%, no mesmo ano, tem mais de $26 \%$ de sua população entre 25 e 64 anos, com ensino superior, somente 3 mortes a cada 1000 nascimentos e apenas 3,6\% das pessoas entre 20 e 24 anos não estuda ou trabalha.

Os dados quantitativos evidenciam a ilusão de que o crescimento econômico, necessariamente, acarreta o desenvolvimento social. A definição de desenvolvimento humano também segue esse pensamento, cujo crescimento econômico não é o suficiente para definir a qualidade de vida da população. Segundo dados do Programa das Nações Unidas para o Desenvolvimento $\left(\right.$ Pnud $\left.^{4}\right)$, para o ano de 2011, a Alemanha ocupa a nona posição no índice do desenvolvimento humano e o Brasil a octogésima quarta posição. De acordo com a Organização das Nações Unidas para a Educação (Unesco ${ }^{5}$ ), no Relatório de Monitoramento Global, de 2011, a Alemanha está em décimo terceiro lugar e o Brasil em octogésimo oitavo no ranking da educação.

\footnotetext{
${ }^{3}$ Dados da OCDE atualizados em janeiro de 2012. Disponível em: http://www.oecdilibrary.org/docserver/download/fulltext/191100371e1t003.pdf?expires=1347368129 \&id=id\&accname=freeContent\&checks um=B9CBD8CDCF334F0CE18FD160F5428E21. Acesso em 11 de setembro de 2012.

${ }^{4}$ Disponível em: http://www.pnud.org.br/atlas/ranking/IDH_global_2011.aspx?indiceAccordion=1\&li=li_Ranking2011 Acesso em 11 de setembro de 2012.

${ }^{5}$ Disponível em: http://www.unesco.org/new/fileadmin/MULTIMEDIA/HQ/ED/pdf/gmr2011-efa-development-index.pdf . Acesso em 11 de setembro de 2012.
} 
Diante dessa situação, os especialistas em áreas distintas da ciência, economia e política, apoderaram-se do discurso da necessidade de educação científica para atingirmos as metas do desenvolvimento econômico. Essa questão fica nítida no relatório de ciência, tecnologia e inovação, recentemente publicado pela Sociedade Brasileira para o Progresso da Ciência (SBPC), que diz o seguinte:

\begin{abstract}
A base científica e tecnológica do país precisa ser ampliada, sobretudo para impulsionar a competitividade das empresas brasileiras e contribuir para a criação de um parque industrial sólido nos setores de alta e média-alta intensidade tecnológica (...). Notoriamente, o problema (baixo desenvolvimento da indústria no Brasil) tem origem no frágil ensino de ciências e de matemática oferecido na educação básica, no reduzido número de escolas de ensino superior de engenharia e de ciências de boa qualidade, e no ainda restrito sistema de pesquisa, desenvolvimento e inovação (P, D \& I) do país (SBPC, 2011, p.3).
\end{abstract}

A nosso ver, o ensino de ciências deve ser mais abrangente que a visão apresentada anteriormente, pois o Brasil ainda é um país agrícola, como pode ser observado na análise do Instituto de Estudos para o Desenvolvimento Industrial ( Iedi $^{6}$ ). Assim, muitas mudanças devem ocorrer na educação, na política e na economia para nos inserir em um quadro justo de desenvolvimento social, pois "o único setor industrial a apresentar superávit foi o de baixa intensidade tecnológica, US\$17,5 bilhões, e ajudou a alavancar o saldo positivo do semestre" (SBPC, 2011, p.18).

Segundo a OCDE, o setor de baixa intensidade tecnológica compreende a produção nos setores da reciclagem, madeira, papel e celulose; editorial e gráfica; alimentos, bebidas e fumo; têxtil e de confecção, couro e calçados. De acordo com estas preposições, fica evidente a necessidade de investimento nos campos da ciência, tecnologia e inovação, mas há problemas ainda muito práticos e graves nos setores primários, como a agricultura.

Assim, há disparidades acerca das concepções sobre formação em ciências: que seja voltada para constituir força de trabalho, para formar cientistas ou para que os cidadãos compreendam e participem das discussões em ciência e tecnologia (C\&T), as quais influenciam suas vidas?

Nesse contexto, é necessário repensar o ensino de ciências, principalmente, frente às questões sociocientíficas, em que a população precisa, com urgência, compreender e participar das discussões. Um exemplo deste tipo de questão é o acidente com o césio-137, em Goiânia, que completa o vigésimo quinto aniversário em 2012. Nesse episódio trágico, cidadãos comuns manusearam o material radioativo, por desconhecer suas propriedades,

${ }^{6}$ Disponível em: http://www.iedi.org.br. Acesso em 10 de setembro de 2012. 
acarretando quatro mortes imediatas e inúmeras outras no decorrer dos anos. Mais recente, foi o caso de contaminação por agrotóxico do leite materno, em Lucas do Rio Verde/MT, em que o excesso e o uso incorreto de agrotóxicos têm acarretado incontáveis problemas à população. Os exemplos nos mostram como devemos nos questionar sobre quais as prioridades do ensino de ciências, em países em que é urgente alfabetizar cientificamente a população.

Diante estas situações, os proponentes da educação CTSA (ciência, tecnologia, sociedade e ambiente) têm em mente o descontentamento com as ações e os processos da ciência e tecnologia (C\&T), quando relacionadas aos aspectos éticos, ambientais e de risco (SANTOS, 2011; SADLER, 2011; MARTINS; PAIXÃO, 2011; PEDRETTI, 2003). Também, há certo descontentamento com a participação da sociedade nas questões controversas de C\&T. Por isso, Pedretti (2003) propõe o trabalho com as questões sociocientíficas (QSC) em sala de aula, como expressão nos currículos e na organização didática do envolvimento dos alunos nos temas polêmicos que envolvem c\&t com aspectos sociais e ambientais.

Em síntese, diversas perspectivas coexistem para propor a educação científica segundo os pressupostos do movimento CTSA. Santos (2011) ressalta as disparidades dos objetivos da educação científica e propõe o movimento CTS para consolidar esta modalidade da educação para a formação para a cidadania. Para esse autor, "o movimento CTS no ensino de Ciências contribuiu para a inserção de temas sociocientíficos, como engajamento em ações sociais responsáveis, questões controversas de natureza ética e problemas ambientais contemporâneos" (p.23).

Pedretti e Zanir (2010), ao analisar as quatro décadas de trabalhos de pesquisa do movimento CTSA, na educação, assumem que há muita confusão e perplexidade em torno do slogan CTSA, pois "não há correntes mutuamente exclusivas, mas sim correntes discerníveis ou coleções de idéias que se unem para formar rotas potenciais disponíveis para professores e acadêmicos sobre como eles podem navegar nas águas da educação CTSA" (PEDRETTI; ZANIR, 2010, p.3, tradução nossa).

Para as autoras, a educação CTSA é um "guarda-chuva" para designar diferentes tipos de teorias sobre as conexões entre ciência, tecnologia, sociedade e ambiente, cujas QSC estão inclusas. Assim, as QSC se opõem ao fosso existente entre o ensino de ciências e a ciência com relações sociais, e se caracterizam como:

Questões sociais controversas com relações conceituais e/ou processuais com a ciência (SADLER, 2004). Elas são problemas abertos sem soluções claras; de fato, 
elas tendem a ter múltiplas soluções plausíveis. Estas soluções podem ser baseadas em princípios científicos, teorias e dados, mas as soluções não podem ser totalmente determinadas pelas considerações científicas. As questões e os potenciais cursos de ação são influenciados por uma variedade de fatores sociais, incluindo política, economia e ética. QSC podem ter natureza global, como a mudança climática e o uso de tecnologias genéticas, ou local, como uma crise ambiental em um bairro ou a determinação da localização de uma nova indústria (SADLER, 2011, p.4, tradução nossa).

Como citamos anteriormente, um exemplo atual destas questões está relacionado ao uso e à contaminação humana, animal e ambiental por agrotóxicos. Um dos agravantes destas discussões está em como introduzir a questão na escola, pois, como afirmam Rozemberg e Peres (2003), um dos grandes problemas educacionais das áreas rurais teve início concomitante ao uso dos agrotóxicos no Brasil, por volta dos anos 60, do século passado. Isso porque a educação voltada para essa parte da sociedade se baseava, inicialmente, em melhorar as técnicas de plantio e diminuir o êxodo rural. Com o início da utilização de agrotóxicos, a educação passou a ser dirigida a que os agricultores aprendessem a manusear tais substâncias.

Atualmente, essas autoras apontam para a necessária educação para o uso correto e a diminuição das contaminações por agrotóxicos. Entretanto, a informação que é levada para o campo, ainda fica a cargo de engenheiros agrônomos, normalmente, representantes das empresas que fabricam agrotóxicos.

Diante da necessidade da formação prática e conceitual sobre os agrotóxicos, questionamo-nos sobre quais os conhecimentos necessários para que agricultores e o público em geral possam se posicionar sobre a questão? Esse posicionamento também se refere a cobrar das autoridades responsáveis políticas públicas para baratear os custos dos agrotóxicos menos ofensivos, saber quais as reais consequências à saúde e ter acesso às maneiras de prevenção e tratamento das doenças decorrentes da contaminação por agrotóxicos. Ainda incluímos nesta lista, a cobrança de ações eficientes contra a entrada de substâncias proibidas e do uso indiscriminado no país.

Para tanto, os conteúdos disciplinares, necessários para tal compreensão, não se restringem aos conceitos científicos. Ao contrário, tratam-se das discussões éticas, sociais, ambientais, discussões sobre risco e análise dos argumentos a que se propõe o tratamento das QSC em sala de aula.

Primeiramente, discutimos a terminologia empregada para designar as substâncias às quais nos referimos como agrotóxicos. Há inúmeras instâncias que defendem a utilização do termo 'defensivos agrícolas', já que os mesmos servem para defender as lavouras das pragas. 
Entretanto, segundo a lei que regulamenta a existência e o uso de agrotóxicos no Brasil, a Lei nº 7802 , de 11 de julho de 1989, os agrotóxicos são definidos, nessa terminologia, como:

a) os produtos e os agentes físicos, químicos ou biológicos, destinados ao uso nos setores de produção, no armazenamento e beneficiamento de produtos agrícolas, nas pastagens, na proteção de florestas, nativas ou implantadas, e de outros ecossistemas e também de ambientes urbanos, hídricos e industriais, cuja finalidade seja alterar a composição da flora ou da fauna, a fim de preservá-las da ação danosa de seres vivos considerados nocivos; b) substâncias e produtos, empregados como desfolhantes, dessecantes, estimuladores e inibidores de crescimento (SISLEGIS, $\mathrm{s} / \mathrm{p}, 2012)$.

Entretanto, Peres, Moreira e Dubois (2003) controvertem as demais denominações dos agrotóxicos, como os defensores agrícolas, remédios e pesticidas. Para os autores:

A denominação pesticidas, mantida pelo forte lobby da indústria química internacional, também reforça o caráter positivo do termo (pesticida, produto que mata - somente - as pestes) e cai como uma luva ao ratificar seus interesses através da consolidação de tais produtos como insumos indispensáveis (segundo profissionais ligados a esses setores produtivos) ao processo de produção rural. $\mathrm{Na}$ literatura de língua espanhola, tais produtos são tratados por "praguicidas" (plaguicidas), com clara associação à denominação de pesticidas (PERES; MOREIRA; DUBOIS, 2003, p.23).

Atualmente, a crença dos agricultores e o discurso da indústria é a de que "não existem alternativas ao uso destes produtos na lavoura, afirmação determinista controlada pela indústria química através dos seus diversos meios de comunicação" (PERES; ROZEMBERG, 2003, p.334). De fato, é reconhecido o papel dos agrotóxicos na economia de um país e no abastecimento contínuo de alimentos para seus habitantes e para a exportação, mas é necessário compreender todos os aspectos contraditórios desta situação.

Por um lado, a população está crescendo e, com isso, deve crescer a produção de alimentos. Por outro, ainda não fomos capazes de sanar problemas antigos, como a miséria dos países da África, mesmo com a utilização dos agrotóxicos. Por quê? Também, mesmo com o desenvolvimento da ciência e da tecnologia, a maioria dos agrotóxicos é nociva à saúde, e os menos nocivos são caros, sob o argumento de demandarem mais pesquisas e investimentos. Alguns estudos buscam reunir informações que associem os agrotóxicos ao desenvolvimento de doenças, como câncer, deformações em fetos e a problemas psicológicos, que acarretam suicídio (PIRES; CALDAS; RECENA, 2005).

Nesse contexto, as consequências à saúde humana são mais visíveis nas pessoas que interagem com essa substância diretamente. Mas, quais as consequências, em longo prazo, para a população que ingere os agrotóxicos em poucas quantidades, durante toda a vida? 
Como identificar as doenças decorrentes da ingestão desses produtos? E como evitar o consumo?

Assim, parece que ainda é incomensurável a relação entre a necessidade do uso dos agrotóxicos, para a produção de alimentos em larga escala, e a as suas relações com moléstias humanas. E o desenvolvimento científico-tecnológico, para a produção de agrotóxicos menos nocivos e tratamento dos seus danos à saúde, ainda é regido de acordo com os interesses econômicos das empresas.

\section{METODOLOGIA DO TRABALHO}

Como nos referimos anteriormente, a metodologia de trabalho com a pesquisa participante foi um meio para integrar a formação de professores, na interação entre universidade e escola. E, para a compreensão das situações que propomos, a análise de conteúdo é apresentada como metodologia para a sistematização dos dados. Ainda salientamos que os dados apresentados neste trabalho constituem apenas parte da totalidade de situações que são interpretadas em uma pesquisa de doutorado.

Segundo Gajardo (1986), na América Latina, há diferentes definições e experiências que se denominam "pesquisa participante". "Existem, isso sim, tradições de pensamento e práticas diversas que conferem alcance e significados diferentes a esse tipo de atividade" (p.11). Mas, em busca de uma definição, a autora compreende tal enfoque como o esforço para desenvolver pesquisas condizentes com a realidade de países da América Latina, que vinculem a produção e a comunicação de conhecimentos à transformação sociopolítica.

Para o trabalho que desenvolvemos, a definição de pesquisa participante de Gajardo (1986) é a que melhor se adéqua, cuja terminologia "é utilizada para designar esforços diversos para desenvolver práticas de pesquisa que incorporem os grupos excluídos das esferas de decisão à produção e comunicação de conhecimentos, como as ações que disso possam derivar" (p.44).

A autora delimita os processos da pesquisa participante nos seguintes aspectos: a) são baseados nas necessidades de grupos social e politicamente marginalizados; b) o ponto de partida, o objeto e a meta da pesquisa são o processo de aprendizagem dos que fazem parte da pesquisa; c) há a interação entre o pesquisador e o grupo que é interpretado; d) busca a comunicação horizontal entre os participantes, inclusive na orientação da pesquisa; e e) utiliza 
o diálogo como meio de comunicação mais importante no processo conjunto de estudo e coleta de informação (GAJARDO, 1986, p.45). Julgamos esse último aspecto o mais marcante na pesquisa participante, já que este tipo de pesquisa rompe com o 'monopólio' do conhecimento, com a participação ativa dos envolvido na compreensão da situação estudada.

Para essas compreensões, seguimos a metodologia da análise de conteúdo (AC), que, segundo Moraes (1999), "ajuda a reinterpretar as mensagens e a atingir uma compreensão de seus significados num nível que vai além de uma leitura comum" (s/p). O autor julga ser essencial na análise de conteúdo, a categorização, a descrição e a interpretação, cujas estratégias de indução e intuição atingem níveis de compreensão mais profundas dos fenômenos.

De acordo com Bardin (1970; p.89-95), a análise de conteúdo deve conter: 1) uma préanálise, que consiste na fase de organização do material; 2) a exploração do material, processo de codificação dos dados brutos de acordo com seus elementos comuns; e 3) o tratamento dos resultados, que corresponde à inferência e à interpretação dos dados obtidos na pré-análise. Sob esta concepção, a AC busca por fatos além da percepção primeira e das supostas transparências.

\section{COMPREENSÕES}

Os registros para a pesquisa foram iniciados em meados de 2011, com o acompanhamento semanal do PGP da cidade de Arealva/SP. Os professores foram convidados a participar do grupo durante o planejamento anual da escola, em que professores pós-graduandos de uma universidade da cidade vizinha realizaram algumas atividades referentes ao tratamento de QSC. Nessas reuniões semanais, foram discutidos textos referentes aos interesses do PGP, análises da escola e das práticas dos professores e ações a serem desenvolvidas pelo grupo. Além de leituras referentes ao tema "Agrotóxicos: custo versus toxidade", como questão sociocientífica proposta pelo grupo.

Além das gravações em áudio, os dados são constituidos nessa escola por meio dos relatos, que são feitos pelos integrantes na lista de e-mails, após cada reunião. Também houve uma entrevista focal, realizada por uma professora do grupo com todos os integrantes, a partir da qual pudemos ter acesso aos dados pessoais dos professores, como idade, tempo de docência e disciplina ministrada. Nessa entrevista foi possível traçar o perfil social do grupo, 
além do interesse de pesquisa da professora em discutir as motivações dos professores ao participarem do PGP.

\begin{tabular}{cccc}
\hline Agente & Idade (anos) & Formação & $\begin{array}{c}\text { Tempo de docência } \\
\text { (anos) }\end{array}$ \\
\hline Professor B & 28 & Licenciatura em Física & 6 \\
Professora AL & 36 & Letras & 14 \\
Professora HE & - & Educação Física & 7 \\
Professora SG & 46 & Licenciatura em História & 23 \\
Professor GB & 30 & Sociologia e História & 5 \\
Professor FL & 34 & Licenciatura em Química & 9 \\
Pesquisadora & 27 & Licenciatura em Física & 5 \\
Mestrando & 23 & Licenciatura em Física & 1 \\
Professora AF & 40 & Letras, Português e Espanhol & 18 \\
\hline
\end{tabular}

Tabela 1: Participantes do pequeno grupo de pesquisa de Arealva/SP

Assim, as categorias e subcategorias que descreveremos a seguir, correspondem ao processo de construção dos conhecimentos novos deste grupo, o que apenas foi possível com o envolvimento e o compartilhamento dos integrantes.

Nos atos de fala que buscamos compreender, aparecem aspectos das questões sociocientíficas que foram apresentados por diversos agentes do PGP, cada um com seu entendimento. A partir dos diálogos, foi possível constituir uma compreensão comum do que eram, inicialmente, informações fragmentadas, e passaram a constituir conhecimentos para a prática docente com as questões sociocientíficas na sala de aula, mais especificamente, com os agrotóxicos: toxidade versus custos.

\section{MOTIVAÇÕES E PROLEMATIZAÇÕES INICIAIS}

Nas primeiras discussões, foram levantadas as condições socioeconômicas e culturais da escola. Assim, foi possível o reconhecimento da necessidade de se trabalhar a QSC relacionada com a temática dos agrotóxicos, com relações com a realidade local e a necessidade de formação para a ação dos alunos da escola que residem e trabalham na área rural. Nas falas abaixo, encontramos elementos da motivação do trabalho com esses alunos e as problematizações feitas pelos professores sobre a temática.

Professor B - por que a gente já tem o que? O público. A gente já tem...mesmo que seja por um motivo que não seja o conhecimento, a gente já tem um motivo que eles (os alunos) querem vir pra escola, então a gente propõe pra gente pensar com carinho o período da tarde, desenvolver atividades, sequências didáticas 
com o período da tarde, por que? A gente coloca que o tema de Arealva, pra gente ter uma questão sociocientífica, Arealva tem um município bem destinado à parte rural, a gente tem essa riqueza.

Professora AF - eu acho que tem que enfatizar nesse projeto, a extensão do município e os problemas decorrentes dessa extensão, que acabam influenciando na própria escola. Então, esse argumento não pode ser para o aluno da manhã, porque ele não vai sair três horas da manhã de casa. Então, essa não é uma questão de discriminação, essa é uma questão objetiva, gente. É uma questão de logística.

Nessas falas, os professores apresentam o problema da cidade, que possui uma vasta extensão territorial, o que complica a vinda dos alunos da área rural para a escola, que saem cedo de casa para estudar no período da tarde. Ainda a seguir, encontramos falas que problematizam a concepção da mídia acerca do problema, e o professor aponta como é possível partir da divulgação midiática para o trabalho em sala de aula:

Professor B - Essa divulgação no Jornal Nacional e no Fantástico fez com que a região que tem como base o comércio do pimentão tivesse muito prejuízo. Consequência desse prejuízo: agora em janeiro, a fiscalização em Arealva aumentou e também influenciou o nosso trabalho que era a partir do estudo da berinjela a fazer entrevistas com os pequenos produtores e levantar quais informações eram importantes para eles. E a partir dessas informações, a gente identificar conteúdos de física e de química e trabalhar na escola.

Nos atos de fala acima, podemos reconhecer aspectos das QSC, como a informação ideológica da mídia: "Essa divulgação no Jornal Nacional e no Fantástico fez com que a região que tem como base o comércio do pimentão tivesse muito prejuízo" (Professor B). Também como a temática que faz parte da vida dos agentes do grupo: "A escolha de se estudar a berinjela é porque o professor $\mathrm{F}$ relatou que quando ele precisava combater os ácaros da sua cultura, os agrotóxicos, ele vem com um manual e nesse manual não havia indicação de como se usar para essa cultura da berinjela". E como a questão leva em consideração o conhecimento científico: "E a partir dessas informações, a gente identificar conteúdos de Física e de Química e trabalhar na escola” (Professor B).

\section{AS QSC FAZEM PARTE DAS VIDAS DAS PESSOAS}

Um dos aspectos que mais contribuiram para a aproximação dos professores ao PGP, e que os motivava para o trabalho em sala de aula, era o fato de que a maioria das pessoas da cidade possui familiares que já tiveram algum problema de saúde relacionado aos agrotóxicos. Além disso, alguns professores também possuem pequenas propriedades agrícolas, participam de associações de agricultores e apresentam problemas pessoais relacionados à temática dos agrotóxicos. Nesse sentido, constituímos uma categoria que 
expressa a importância deste caráter das questões sociocientíficas. Nas falas a seguir, encontramos o relato dessa situação:

Professora SG - Qual o recorte? Qual seria o efeito dos agrotóxicos nos agricultores arealvenses? Será que realmente essa informação, será que foi só minha família, né? Será que esse dado que foi levantado inclusive em relatos médicos do agrotóxico com o câncer específico? Será que acontece com outras pessoas da comunidade? Porque aqui em Arealva tem bastante incidência de câncer, isso é preocupante. De onde vem? E, no caso, na época, eles estavam discutindo a questão do suícidio também, inclusive, a pessoa que se suicidou foi lá, comprou o veneno tranquilamente na loja, né, e tomou. Não há controle nenhum em cima disso. É pra pensar.

Professor FL - Eu faço parte da associação e tem sempre gente nova chegando, sem noção nenhuma, mas diz que vai plantar pimentão porque dá dinheiro. Então, isso aumenta o problema da contaminação. Então, foi muito legal conhecer, já tinha ouvido falar das questões sociocientíficas, mas nunca tinha trabalhado. Daí conciliou uma coisa que, pelo menos eu achava que seria interessante trabalhar com Arealva, isso que está me motivando a continuar, tenho um certo conhecimento do problema e acho interessante trabalhar com isso e acho que vai ser viável. Essa é pelo menos a ideia inicial né, precisava dar uma melhorada né...assim...

A importância desta característica também está relacionada à sala de aula, pois, segundo Ratcliffe e Grace (2003), as QSC podem ter caráter local ou global, mas a sua abordagem permite aos estudantes atuarem tanto em associações e ações em sua comunidade, como é emergência da temática que desenvolvemos, como desenvolver uma reflexão que os permita compreender e participar de discussões mais abrangentes. Nesse sentido, questões muito distantes dos alunos podem não envolvê-los no debate e, portanto, desmotivar o trabalho do professor.

\section{NECESSÁRIA INFORMAÇÃO}

Nas falas a seguir, o professor reconhece que o papel da informação é limitado, mesmo após demonstrar conhecimentos importantes sobre o assunto, assume que algumas relações entre ciência e tecnologia fogem ao seu conhecimento. Esta situação é visível, principalmente, nas ações dos produtores, ao falar sobre o custo alto do desenvolvimento de pesquisas e produção de agrotóxicos menos tóxicos e sobre o uso do EPI (equipamento de proteção individual). Assume-se também que a informação não tem uma relação direta com a consciência e, necessariamente, a ação. Mesmo sendo professor, há situações complexas que retratam o cotidiano dos alunos, que demandam conhecimentos não escolares. Ainda assim, a escola e a comunidade possuem papel importante na construção dos conhecimentos sobre a temática, alguns destes conhecimentos são apontados pelos professores:

Professor FL - eu já tive empregado que queria experimentar o agrotóxico, porque tinha um cheiro gostoso, porque o inseto, ele tem uma afinidade muito grande com o açúcar, então tinha um produto que vinha 
com o melaço de cana, que era doce, então, com isso você passava e tinha uma ação maior. Mas daí eu cheguei lá e o cara tava falando "nossa, mas que cheiro gostoso". Isso aconteceu comigo mesmo, parece cômico.

Professor FL - eu comecei a falar para eles, porque alguns alunos, que ficaram dispersos, que na hora que a gente tava falando, eles não...daí eu falei pro menino, você já passou agrotóxico, não é? Já teve vez que você passou e não deu resultado, não é? Porque o PH da água tem a ver com o agrotóxico, daí eles começaram a se sentir interessados, o controle de PH é extremamente importante porque você atinge $100 \%$ do veneno, então às vezes, você passa, mas não dá o resultado esperado, mas porque o PH da água não tá adequado, daí ele aumenta a dose e vê o que tá acontecendo né.

Professor FL - o aluno tava passando mal e eu perguntei o que aconteceu, daí ele falou "ah, é que eu tava...passei a tarde inteira lavando embalagem pra poder devolver, porque não podia entregar suja". Daí eu perguntei se ele não usou máscara, nem nada, ele falou "não". Então, você vê que o projeto (campo limpo) é excelente, só que você vê como a falta de informação, porque ele teria que usar a máscara pra lavar, só que aí ele ia fazer o que? Ele ia lavar pra jogar no meio ambiente. Então, eles iam tá recolhendo a embalagem, mas olha como gera problema.

Nesse conjunto de atos de fala, o professor faz o reconhecimento de agravantes do tema em diversas perspectivas, mas, em todas elas, a informação é o elemento principal. Primeiramente, devido ao desconhecimento dos princípios ativos dos produtos, que remete à formação técnica-científica dos sujeitos, além da submissão ao técnico agrícola ou agrônomo, que tem a função de instruir os agricultores, mas acabam agindo em função das empresas que trabalham. Ao se referir ao projeto "campo limpo", que visa ao recolhimento das embalagens vazias de agrotóxicos, o professor também ressalta a ineficácia de ações pontuais, que pouco contribuem para sanar os problemas causados pelo descarte dos agrotóxicos na natureza e para a formação e informação dos sujeitos. Em sua fala, é possível reconhecer a situação controversa entre as ações governamentais e as relações entre ciência, tecnologia, sociedade e ambiente. A incoerência é presente, principalmente, ao descrever a necessidade da tríplice lavagem para a entrega das embalagens de agrotóxicos, que são feitas por alunos adolescentes da escola. Sobre esta situação, houve relatos de alunos que tiveram problemas de saúde após o procedimento.

\section{CONTRAPOSIÇÃO DOS ARGUMENTOS}

Os aspectos levantados anteriormente apontam que o trabalho com as QSC em sala de aula deve ir além da conscientização sobre os riscos da utilização dos agrotóxicos. É necessário ponderar argumentos e chegar às ações efetivas com os alunos. Nesse sentido, reforçamos nossa concepção de que as QSC devam acarretar a compreensão e a participação pública em temas polêmicos que envolvem ciência e tecnologia, para tanto, é necessário que 
os alunos compreendam as diversas perspectivas que discutem a temática. Nas falas a seguir, são inseridas algumas dessas visões:

Professor FL - o ultimo produto que eu comprei para fazer um tratamento na área, ele é um fungo, faz o controle biológico, ele fica em $\mathrm{R} \$ 360,00$ pra tratar aquela água, se eu fosse comprar outro produto similar ficaria em $\mathrm{R} \$ 25,00$ só que ele é extremamente tóxico e tem o intervalo de segurança de dois meses e esse fungo né...então, é uma coisa que eu não consigo entender nessa parte, já é um problema que...eu não sei o que, qual o interesse da indústria ou o que acontece pra ter essas coisa né. Têm produtos baratos né, mas geralmente, na média, quanto mais tóxico, mais barato.

Professor FL - O problema é que os agrotóxicos utilizados, embora deem conta da praga do pimentão, como eles não eram registrados para o pimentão, isso foi o que gerou a polêmica de que o pimentão não poderia ser consumido ou que ele tinha altos níveis de agrotóxico. O problema não é a concentração do agrotóxico, mas do tipo de agrotóxico que foi utilizado não era o indicado, não tinha uma legislação responsável que falava "ó, está autorizado a utilizar para o pimentão”. Então, se nós continuássemos a nossa ideia inicial de desenvolver o estudo da berinjela e como adaptar um agrotóxico não habilitado pra berinjela na agricultura, a gente ia tá contribuindo pra prejudicar o comércio. Então, esse é um problema que a gente vai ter que cortar agora esses estudo e começar agora com o pimentão.

Os professores também reconheceram os argumentos econômicos e de grupos de interesse que influenciam na controvérsia da questão dos agrotóxicos:

Professor FL - O problema não é a concentração do agrotóxico, mas do tipo de agrotóxico que foi utilizado não era o indicado, não tinha uma legislação responsável. Então, nesse caso a análise quando chega o produto lá no SEAGESP, eles pegam algumas amostras do pimentão e fazem a análise. Tinha um problema realmente do excesso de agrotóxicos, mas também eles analisam se o produto é registrado para o pimentão ou não. Aí também entra no índice de contaminação. Então esse que era a grande preocupação deles, né, da mídia, que nem a Pesquisadora tava falando, a mídia influenciou e só falou isso. Mas o pimentão tem algumas doenças que ele não tem produto registrado, aí o que eles falavam lá são três problemas: é muito caro pra registrar, é muito demorado, né, e em consequência a burocracia é muito grande. Aí acaba sendo um problema.

Nessa direção, Fullick e Ratcliffe (1996) ainda atentam para o tratamento da temática dos agrotóxicos, segundo aspectos éticos:

Frequentemente, nós encontramos imperativos éticos diferentes e conflitantes, e.g. o uso de pesticidas para melhorar a produção de alimentos onde há pessoas famintas, não utilizar pesticidas porque eles arruínam o ambiente. É importante para os estudantes observarem que os imperativos éticos são, eles mesmos, abertos a discussão, comparação e avaliação (p. 38). 
Assim, o entrelaçamento das diferentes perspectivas sobre o assunto permite que os alunos possam reconhecer o caráter ideológico das informações e, a partir disso, se posicionar reforçando os argumentos que corroboram a sua visão. Parte destes argumentos pode ser sustentado com os conhecimentos curriculares, como destacamos na próxima categoria de análise.

\section{CONTEÚDOS CURRICULARES}

Nas falas das professoras a seguir, há a localização dos conteúdos curriculares que se relacionam com a temática dos agrotóxicos. Esta situação é necessária, na medida em que o projeto desenvolvido também corresponde à organização da escola, mas permite que os professores desenvolvam seus próprios currículos. Isto denota a possibilidade de aumento no grau de criatividade dos professores ao transitar por diferentes âmbitos da realidade da escola e da comunidade e voltar o ensino para as necessidades de seus alunos.

Professora AF - Bom, as competências de habilidades, distinguir enunciados e objetivos de subjetivos, né, opinião não é totalmente objetiva, né, o que é fato é que é objetivo. Opinião é subjetiva. Reconhecer as linguagens que são integradoras de comunicação. Quais estratégias aí nós utilizaríamos nesse sequencia didática. A interativa com participação dialógica do aluno, $\mathrm{O}$ que é isso? O aluno vai ajudar a construir o conhecimento. E na experiência que eu tive com a... Tanto com a segunda série quanto com a terceira, tanto da manhã quanto da tarde, eles devolvem isso. Então isso vai fazer com que esse conhecimento ele seja importante para o aluno. Quer dizer, eu vou... Através do diálogo construir o conhecimento. As estratégias, né, o professor deve saber que estratégias ele vai utilizar na sala de aula. O uso de recursos audiovisuais, a valorizção do cotidiano escolar e um aprendizado ativo, centrado no fazer do aluno, porque esse é... Não o professor lá e vai com aquela educação bancária, né, como fala o Paulo Freire.

Professora SG- Então nós vamos construir a memória através de relatos elaborais e entrevistas e essa opção tá dentro do caderninho "São Paulo faz escola", tá? Só lembrando que fonte significa limpidez, clareza, pureza e a importância do relato das informações, das entrevistas né, serem o mais fiéis possíveis. Tem que ser confiável e segura. Então, tá na hora de anotar os relatos.

Assim como na fala da Professora AF, temos como premissa que o trabalho com as QSC possibilita que o aluno se desenvolva em termos da competência argumentativa e na compreensão dos conteúdos científicos, como meios de sua participação nas decisões em ciência e tecnologia. Por outro lado, devemos refletir que a proposta de trabalho com as QSC possibilita que os professores críticos reconheçam o caráter prescritivo dos currículos e propostas curriculares, ao mesmo tempo em que atentam para os conhecimentos necessários para que os alunos compreendam e se posicionem acerca da questão. 
Por exemplo, se o objetivo principal do ensino de ciências é aumentar a compreensão dos princípios científicos dos estudantes, os educadores de ciências então não precisam se preocupar com as dimensões dos objetivos mais instrumentais, que podem apresentar desafios pedagógicos complicados. Se o principal objetivo do ensino de ciências é apoiar as habilidades dos estudantes para se engajar em práticas científicas, as oportunidades educacionais, então devem ser projetadas de tal forma que maximizem o envolvimento dos alunos nessas práticas. Isso pode significar que as metas mais instrumentais, como carreira e/ou preparação para a cidadania seriam desenfatizadas removidas do currículo (SADLER, 2011, p.3).

Após algumas discussões, a Professora AF ressaltou em suas falas a necessidade de que o trabalho com as QSC devesse "servir" aos alunos, já que a escola apresenta bons índices de redação nas avaliações em larga escala, que normalmente, permeiam temas polêmicos presentes na mídia. Portanto, a proposta que inicialmente deveria retomar o universo temático dos alunos passou a ter uma conotação instrumental, como podemos acompanhar nos atos de falas a seguir.

\section{ASPECTOS INSTRUMENTALIZADOS}

Embora tenhamos apontado para o reconhecimento de diversos aspectos das QSC pelos professores, no início do trabalho, alguns aspectos destas questões ainda eram entendidos de maneira pouco crítica ou como prática voltada apenas para a melhoria dos índices de aprovação da escola. A esses aspectos, denominamos instrumentalizados, já que não correspondem à concepção de formação que descrevemos, segundo o movimento CTSA e as QSC, como formação para a argumentação dos alunos, que podem representar esta possibilidade em diversos momentos de sua vida escolar e social, incluindo nas argumentações das redações solicitadas nas avaliações em larga escala, como o Exame Nacional do Ensino Médio (ENEM). Um pensamento apenas estratégico, em função do treinamento sobre temas das provas em larga escala, não corresponde aos propósitos das QSC em sala de aula.

Elementos desta natureza podem ser apresentados na fala da professora a seguir:

Professora AF - ela ajuda muito, a Professora HL, eu tava comentando com ela como professora de português, as nossas notas do ENEM, nós somos a escola pública de melhor nota da região de Bauru. Então, eu to super feliz essa semana, porque não é aquela escola pública que tá passando na televisão como péssima, quer dizer, nós temos uma escola pública que, dentro cem da região, nossa nota de redação é quase igual à média das particulares de Bauru. No estado, entre as 
particulares e as públicas nossa colocação é 1200, tem vinte e sete mil. No Brasil, entre as públicas e as particulares, a nossa colocação é mais ou menos quatro mil. Então, eu acho assim, como que a gente consegue mostrar que esse trabalho tá dando certo? É com número, infelizmente é com número.

\section{Professor B - também.}

Professora AF - porque, como eu vou poder falar com o pai, que o trabalho que eu to fazendo é bom, sendo que ele ta vendo toda hora na televisão que não é? Então eu acho que foi muito bom pra escola o ensino médio ter tirado essa nota.

Professora AF - porque aí eu já fico com...daí eu como professora de português, eu to com que parte do caderno? Os temas que podem cair na redação do ENEM. Então, eu tenho que pensar que meu aluno tá preparado pra escrever sobre esses temas, então até que ponto um tema desses é importante pro meu aluno? Então, na verdade eu só penso...

Professor $\mathbf{B}$ - referente às avaliações externas...

Reis (2006) aponta para as constantes prescrições curriculares e avaliações em larga escala, que condicionam os professores em práticas e temas tradicionais. Nesse sentido, os estudos e pesquisas com as QSC, em sala de aula, devem ser voltados primeiramente para a compreensão dos aspectos formativos de tal abordagem.

Entretanto, mesmo que a fala se remeta a uma visão diretamente ligada aos imperativos do sistema escolar, a existência desta discussão no PGP possibilita o reconhecimento das imposições que as avaliações em larga escala e os currículos padronizados podem levar para os professores. Isto porque, as compreensões que são realizadas nas discussões remontam sempre para a crítica destas imposições, diante de processos de formação mais elaborados e cuidados, que possibilitam que o professor construa seus conhecimentos e currículos acerca da temática.

\section{CONSIDERAÇÕES FINAIS}

O desenvolvimento de uma questão sociocientífica parece ser uma ação que denota o desenvolvimento da identidade e dos objetivos do PGP. Como pudemos acompanhar no PGP de Arealva, a discussão desse tema possibilitou diversos meios para a formação de professores, com estudos de textos acadêmicos e outros documentos de interesse dos participantes, além da realidade da cidade.

Quanto ao desenvolvimento da questão sociocientífica, no pequeno grupo de pesquisa que funciona na escola de Arealva, a temática tem sido trabalhada em diversas disciplinas, segundo os enfoques observados na tabela a seguir e propostos pelos próprios professores: 


\begin{tabular}{|l|l|l|}
\hline Disciplina & Enfoque & Conteúdos \\
\hline Física & Divulgação da ciência & $\begin{array}{l}\text { - modelos atômicos } \\
\text { - interação entre partículas } \\
\text { - Unidades de Medida (Energia de } \\
\text { ignição, massa, volume, densidade, } \\
\text { Tensão Superficial) }\end{array}$ \\
\hline Química & Compreensão e participação em CT & $\begin{array}{l}\text { - elementos químicos } \\
\text { - misturas e soluções } \\
\text { - pH } \\
\text { - ligações químicas }\end{array}$ \\
\hline $\begin{array}{l}\text { Língua } \\
\text { Portuguesa }\end{array}$ & Argumentação & $\begin{array}{l}\text { - produção de textos } \\
\text { argumentativos-dissertativos } \\
\text { - artigos de opinião }\end{array}$ \\
\hline História & História local & $\begin{array}{l}\text { - incidência de câncer } \\
\text { - história oral } \\
\text { - pesquisa de campo }\end{array}$ \\
\hline
\end{tabular}

Tabela 2: Enfoques do trabalho desenvolvido com as QSC na escola do PGP Arealva

Assim como o trabalho que realizamos, Bernardo, Vianna e Silva (2011) relatam um projeto que teve como base os estudos CTS e a formação de professores, para o trabalho com questões sociocientíficas. Esses autores descrevem o processo como:

O processo de construção propriamente dito envolveu, dentre outras atividades, momentos de revisão bibliográfica e discussão do referencial teórico (CTS) para fundamentação das ações do grupo. Em seguida, o grupo definiu temas sociocientíficos de interesse das escolas que funcionaram como estruturadores das propostas, a partir das quais ocorreram os planejamentos das atividades, seleção e desenvolvimento do material didático compatível com as atividades planejadas (BERNARDO; VIANNA; SILVA, 2011, p.383).

As compreensões destes autores, sobre o projeto realizado, estiveram associadas à formação dos professores no trabalho em equipe e à consciência em relação às interações CTS. Além disso, os autores ressaltam como os professores regentes perceberam a necessidade de enfrentar a estrutura fechada das escolas. Há, ainda, outros aspectos que aproximam as duas pesquisas:

Essa relação entre universidade e a escola deve ser de absoluta horizontalidade, e a valorização da escola como espaço de produção de conhecimento e dos saberes dos professores experientes são de fundamental importância para a convivência entre os parceiros (BERNARDO; VIANNA; SILVA, 2011, p.389).

Embora o trabalho referido e o trabalho que desenvolvemos partam de referenciais teóricos diferentes, temos a impressão de que o trabalho intersubjetivo dos professores reflete significativamente em suas práticas com as questões sociocientíficas. Devemos também ressaltar o fato de que os currículos vêm com um caráter fechado nas escolas, mas os professores, em interação, têm encontrado meios de trabalhar com autonomia. 
Reis (2006), em pesquisa realizada acerca da formação de professores para o trabalho com QSC, também encontrou potencialidades na interação entre professores: a) na superação de dificuldades e obstáculos com que deparam na sua atividade profissional; b) na estimulação de uma atitude reflexiva acerca de suas metodologias de ensino e; c) na obtenção da confiança necessária ao envolvimento de novos desafios (p. 98).

Desta forma, as categorias que descrevemos apontaram para características das questões sociocientíficas e revelaram aspectos do crescimento profissional intersubjetivo, que esteve vinculado à elaboração e ao trabalho de uma QSC na escola. Esta situação ainda é caracterizada pela autocompreensão do grupo, pelo diálogo entre universidade e escola, pelas necessidades formativas, pelo questionamento dos documentos oficiais, análise da prática profissional e pelos indicadores de aprendizagem.

Finamente, os professores do PGP passaram a idealizar suas próprias aulas e atividades extracurriculares, a partir da interação comunicativa com os pares. Nessa interação, foi possível conhecer e compreender as QSC, além de desenvolver as sequências didáticas com a ajuda dos colegas. Essa é uma situação incomum às escolas, mas torna-se uma possibilidade para pesquisas e trabalhos futuros para a inserção das QSC nas salas de aula. Assim, reconhecemos que ainda é necessário compreender mais sobre a transição do trabalho que é feito entre os professores, para a produção de sequências didáticas, e como elas são efetivadas em sala de aula. Mas, esperamos que os trabalhos analíticos sobre estas práticas partam das pesquisas que os professores podem desenvolver no PGP.

\section{REFERÊNCIAS}

BARDIN, L. Análise de conteúdo. São Paulo, SP. Ed. 70, 1977.

BERNARDO, José R. R.; VIANNA, Deise M.; SILVA, Vitor H.D. A construção de propostas de ensino em Ciência-Tecnologia-Sociedade (CTS). In: SANTOS, Wildson; AULER, Décio (Orgs.) CTS e educação científica: desafios, tendências e resultados de pesquisa. Brasília: Editora UnB, 2011, p.373-394.

CANÁRIO, Rui. INAFOP, Formação profissional de professores no ensino superior. A prática profissional na formação de professores. Universidade de Aveiro, 2000, p.3.

CONTRERAS, José. A autonomia de professores. Tradução: Sandra Trabucco Valenzuela. São Paulo: Cortez, 2002. 
FULLICK, Patrick; RATCLIFFE, Mary. Teaching ethical aspects of science. Great Britain: The Bassettt Press, 1996.

KEMMIS, Stephen. La formación del profesor y la creación y extensión de comunidades críticas de profesores. Investigación en la escuela, n.19, 1993, p.15-38.

GAJARDO, Marcela. Pesquisa Participante na América Latina. Tradução: Tânia Pellegrini, São Paulo: Editora Brasiliense, 1986.

MARTINS, Isabel P.; PAIXÂO, Maria de F. Perspectivas atuais Ciência-Tecnologia-Sociedade no ensino e na investigação em educação em ciência. In: SANTOS, Wildson; AULER, Décio (Orgs.) CTS e educação científica: desafios, tendências e resultados de pesquisa. Brasília: Editora UnB, 2011, p.135-160, 2011

MORAES, Roque. Análise de Conteúdo. Porto Alegre: Revista Educação, v.22, n.37, p.7-32, 1999. Disponível em: http://cliente.argo.com.br/ mgos/analise_de_conteudo_moraes.html . Acesso em 23-08-2012.

PEDRETTI, E. Teaching Science, Technology, Society and Environment (STSE) Education. In: ZEIDLER, D. (Org.) The role of the moral reasoning on socioscientific issues and discourse is science education. London, Dordrecht, Boston: Kluwer Academic Publishers, p.219-240, 2003.

PEDRETTI, Erminia; ZANIR, Joanne. Currents in STSE education: Mapping a complex field, 40 years on. In: Science Education, 2011.

PEREIRA, J.E.D. A pesquisa dos educadores como estratégia para construção de modelos críticos de formação docente. In: J.E.D.PEREIRA; K.M. ZEICHNER (orgs.) A pesquisa na formação e no trabalho docente. Belo Horizonte: Ed. Autêntica, 2002.

PERES, Frederico; MOREIRA, Josino C.; DUBOIS, Gaetan S. Agrotóxicos, saúde e ambiente: uma introdução ao tema. In: PERES, Frederico; MOREIRA, Josino C. (Orgs.). É veneno ou é remédio? Agrotóxicos, saúde e ambiente. Rio de Janeiro: Editora FIOCRUZ, 2003, p.21-41.

Frederico; ROZEMBERG, Brani. É veneno ou é remédio? Os desafios da comunicação rural sobre agrotóxicos. In: PERES, Frederico; MOREIRA, Josino C. (Orgs.). É veneno ou é remédio? Agrotóxicos, saúde e ambiente. Rio de Janeiro: Editora FIOCRUZ, 2003, p.329-348.

PIRES, D.X; CALDAS, E.D.; RECENA, M.C.P. Intoxicações provocadas por agrotóxicos de uso agrícola na microrregião de Doutorados, Mato Grosso do Sul, Brasil, no período de 1992 a 2002. Caderno Saúde Pública, Rio de Janeiro, 2005, 21(3), p.804 - 814.

REIS, Pedro. Uma iniciativa de desenvolvimento profissional para a discussão de controvérsias sociocientíficas em sala de aula. Lisboa: Interacções, n.4, p.64-107, 2006. 
ROZEMBERG, Brani; PERES, Frederico. Reflexões sobre a educação relacionada aos agrotóxicos em comunidades rurais. In: PERES, Frederico; MOREIRA, Josino C. (Orgs.). É veneno ou é remédio? Agrotóxicos, saúde e ambiente. Rio de Janeiro: Editora FIOCRUZ, 2003, p.367-384.

SADLER, Troy D. Situating sócio-scientific issues in classrooms as a means of achieving goals of science education. In: SADLER, Troy D. (ed.) Socio-scientific issues in the classroom: teaching, learning and research. New York: Springer Science+Business Media, 2011.

SANTOS, Wildson. Significados da educação científica com enfoque CTS. In: SANTOS, Wildson; AULER, Décio (Orgs.) CTS e educação científica: desafios, tendências e resultados de pesquisa. Brasília: Editora UnB, 2011, p.21-48.

SISLEGIS, 2012, Sistema de consulta à Legislação, versão 1.0, acesso em 26 de julho de 2012, disponível em: http://sistemasweb.agricultura.gov.br/sislegis/action/detalhaAto.do?method=consultarLegislacaoFeder al

SOCIEDADE BRASILEIRA PARA O PROGRESSO DA CIÊNCIA. Ciência, tecnologia e inovação para um Brasil competitivo/Sociedade Brasileira para o Progresso da Ciência. São Paulo: SBPC, 2011. 